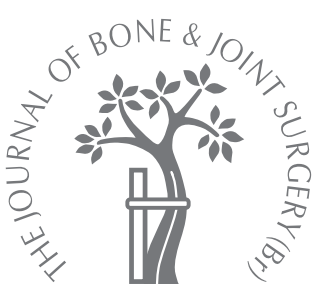

J. A. Singh, M. M. O’Byrne, R. C. Colligan, D. G. Lewallen

From Mayo Clinic, Rochester, Minnesota, United States

J. A. Singh, MBBS, MPH Associate Professor of Medicine

Division of Rheumatology, University of Alabama at Birmingham and Birmingham VA Medical Center

Faculty Office Tower 805B, 510 20th Street South, Birmingham, Alabama 35294, USA.

M. M. O'Byrne, MA Statistical Programmer Analyst Division of Biomedical Statistics and Informatics, Department of Health Sciences Research

R. C. Colligan, $\mathrm{PhD}$, Professor, Psychology Department of Psychiatry and Psychology

D. G. Lewallen, MD,

Professor, Orthopaedic Surgeon

Mayo Clinic, 2001 st Street SW Rochester, Minnesota 55905, USA.

Correspondence should be sent to $\mathrm{Mr}$ J. A. Singh; e-mail: Jasvinder.md@gmail.com

(C)2010 British Editorial Society of Bone and Joint Surgery doi:10.1302/0301-620X.92B6. $23114 \$ 2.00$

$J$ Bone Joint Surg $[\mathrm{Br}]$ 2010;92-B:799-806. Received 20 July 2009; Accepted after revision 3 February 2010

\title{
Pessimistic explanatory style
}

\author{
A PSYCHOLOGICAL RISK FACTOR FOR POOR PAIN AND \\ FUNCTIONAL OUTCOMES TWO YEARS AFTER KNEE \\ REPLACEMENT
}

Seligman's theory of causal attribution predicts that patients with a pessimistic explanatory style will have less favourable health outcomes. We identified 702 patients who had undergone 894 primary total knee replacements between 1993 and 2005, who responded to follow-up surveys at two ( $n=783$ knee replacements) and/or five years ( $n=443$ knee replacements) and had also completed the Minnesota Multiphasic Personality Inventory long before the joint replacement (median $=\mathbf{1 6 . 6}$ and 14.5 years for two- and five-year cohorts, respectively). Scores from the Minnesota Multiphasic Personality Inventory Optimism-Pessimism scale were used to categorise patients as pessimistic (t-score $>60)$ or non-pessimistic ( $t$-score $\leq 60)$. Multivariate logistic regression models assessing the effect of pessimistic explanatory style on pain or improvement in knee function were adjusted for gender, age, distance from the place of treatment and depression score. Pessimists reported (a) significantly more moderate or severe pain at two years with odds ratio 2.21 (95\% confidence interval ( $\mathrm{Cl}) 1.12$ to $4.35 ; p=0.02)$, but not at five years when the odds ratio was 1.21 (95\% Cl 0.51 to $2.83 ; p=0.67$ ); and (b) less improvement in knee function at two years when the odds ratio was $0.53(95 \% \mathrm{Cl} 0.30$ to $0.96 ; p=0.04)$, but not at five years when the odds ratio was 1.26 (95\% $\mathrm{Cl} 0.57$ to $2.77 ; \mathrm{p}=0.57$ ).

No significant associations with moderate or severe limitation of activity were seen at two or five years. We conclude that a pessimistic explanatory style is associated with worse pain and functional outcomes two years after total knee replacement.

A distressed psychological state around the time of surgery, including depression and anxiety, has been associated with poorer pain and functional outcomes at short- and mediumterm follow-up in patients who have undergone total knee replacement (TKR). ${ }^{1-5}$ Although the psychological state may change over time, psychological traits tend to remain stable. It is not known whether certain preexisting, psychological characteristics of these patients, such as optimism or pessimism, affect the outcome after TKR.

In order to investigate this question conceptually, we used Seligman's theory ${ }^{6-8}$ of causal attribution, that is, an explanatory or attributional style. The theory postulates that the manner in which people explain to themselves the reasons for the occurrence of specific, important, good or bad events in their lives, by asking questions such as "Why did this happen to me?", has important ramifications. More specifically, according to this theory, people who 1) attribute the causes of adverse events in their lives to themselves. with an internal explanation, 'It's me...., 2) carry the expectation that the condi- tion will persist, applying a stable explanation, '.....happened again, as usual...' and 3) believe that it will affect other aspects of their life, with a global explanation, '...... and now....I'll never get to....', can be described as having a pessimistic attributional style. The converse characterises an optimistic explanatory style. ${ }^{6-8}$ It has been shown over the past 35 years that a pessimistic explanatory style is a significant risk factor for future episodes of depression, reduced occupational or academic accomplishments, and an increased risk of poorer physical health. ${ }^{9}$

The score from the optimism-pessimism scale of the Minnesota Multiphasic Personality Inventory (MMPI) ${ }^{10}$ preceding the TKR, either primary or revision, was used to classify our patients. ${ }^{11,12}$ Two longitudinal studies have validated Seligman's theory among general medical outpatients. ${ }^{13,14}$ These 30 -year followup projects found that a pessimistic explanatory style, derived from scores on a bidirectional scale of optimism-pessimism using the MMPI item pool, was significantly associated with increased mortality ${ }^{13}$ and poorer selfreported quality of life. ${ }^{14}$ 
The original MMPI consisted of 550 unique true/false items pertaining to thoughts, feelings, attitudes, physical symptoms, emotional symptoms and previous life experiences. Empirical approaches were used to create a profile of scales characterising common psychological and psychiatric conditions. ${ }^{15}$ The MMPI and its current revision, the MMPI- $2,{ }^{16}$ have been the most widely used and thoroughly researched of the self-reporting measures of personality functioning yet developed. ${ }^{17}$

Typically, TKR is a successful surgical procedure associated with a significant reduction in pain, improved knee function and better overall quality of life. ${ }^{18,19}$ However, to our knowledge there are no studies that have determined whether the explanatory style is associated with a better or a poorer outcome. In this study our objectives were to assess whether an explanatory style is independently associated with self-reported (1) pain, (2) limitations in activities after follow-up at two and five years post-primary or post-revision TKR and (3) time to revision or re-operation in patients with primary TKR.

\section{Patients and Methods}

We identified a cohort of 812 patients ( 322 men and 490 women) who had undergone primary or revision TKR between 1993 and 2005, had completed the two- or fiveyear pain, function and activity limitation questionnaire between 1993 and 2007, and also completed a MMPI at any time prior to their index TKR. For this group the median interval from the time of completion of the MMPI to TKR was 16.5 years ( 0 to 42 ). This included 702 patients (275 men, 427 women) with 894 primary TKRs and 143 (61 men, 82 women) with 164 revision TKRs. Some patients had bilateral TKRs and some qualified for inclusion in both primary and revision TKR cohorts during this 12 -year period. Outcomes were derived from a validated pain/function questionnaire ${ }^{20}$ which was sent to the patients for completion and return, or administered in the clinic as part of the regular follow-up. For those who did not respond to the survey and were not attending clinical follow-up, it was administered by telephone interview by trained staff. The study was approved by the Institutional Review Board at the Mayo Clinic.

Predictor of interest. The score from the optimismpessimism scale of the MMPI, preceding the TKR (either primary or revision) was used to classify our patients. Following Maruta et al, ${ }^{13,14}$ we classified patients into two categories: pessimists (T-score $>60$ ) and non-pessimists (T-score $\leq 60)$.

Outcomes of interest. Self-reporting of joint pain, improvement in knee function compared to the pre-operative status and overall limitation of activity were obtained from the follow-up questionnaire for both primary and revision TKR patients. We also calculated implant survival in patients with primary TKR.

Knee pain was assessed by a single question: 'How much pain do you have in your knee that was operated upon'?, to which the seven potential responses comprised; no pain, mild occasional pain, pain only when negotiating stairs, pain while walking and climbing stairs, moderate (occasional), moderate (continuous), and severe. Patients were categorised into two groups derived from their response: 'moderate' and 'severe' were combined; the other categories were combined as the reference group.

Self-reported knee function required comparison to preoperative status. It was also assessed with a single question: 'Compared to your condition before your knee surgery, how would you rate your knee function'? There were four possible responses; much better, somewhat better/better, same, worse. Patients were categorised into two groups, based on their response to this item. We compared patients in the category of 'much better' with those in the reference category comprising 'somewhat better, same, worse', based on the fact that, typically, TKR is an extremely successful procedure and most patients aim to achieve much better knee function than pre-operatively.

The self-reported current status of functional activity for walking, stair-climbing and rising from a chair was obtained by asking about limitations in these three activities and classifying the patients into two groups, using a four-point categorical scale for each activity: (1) Distance walked: unlimited or $>$ ten blocks = none; five to ten blocks = mild; < five blocks = moderate; housebound, indoors only or unable $=$ severe; (2) Climbing stairs: normal up and down = none; Normal up, down with hand rail = mild; up and down with hand rail = moderate; up with rail, down unable or unable = severe; and (3) rise from chair: able, no arms = none; able with arms = mild, able with difficulty = moderate; unable $=$ severe.

The classification into the two groups of functional limitations was based on the extent of the limitation. Those patients who reported moderate or severe limitation in two or more of these three activities were grouped as having moderate-severe limitations overall, ${ }^{21,22}$ and the remainder were classified as having none or only mild limitations, and served as the reference group.

Finally, implant survival was defined as the time from the primary TKR to that of the first revision or re-operation.

Covariates/confounders. Given the creation of these subsets, yielding small numbers of patients with events of interest in some cells, we limited the multivariable analyses to the following, already acknowledged, potential confounders: gender, age in three categories $(\leq 60,61$ to 70 , $>70$ years), ${ }^{23,24}$ depression score (MMPI), ${ }^{25,26}$ and distance travelled from the patient's residence to the place of treatment (Mayo Clinic, Rochester, Minnesota) in three categories ( 0 to $100,>100$ to $500,>500$ miles).

Statistical analyses. Summary statistics are presented for the clinical characteristics of the primary and revision TKR two- and five-year cohorts. Multivariable logistic regression analyses were used to examine the associations between explanatory style, with each patient classified as having a pessimistic or non-pessimistic style, with each 
binary outcome of interest, in the two- and five-year primary TKR cohorts and after adjusting for potential confounders. Similar analyses were performed for revision TKR cohorts, except that small numbers precluded multivariate analyses for the five-year revision TKR cohort.

The explanatory variables in the multivariate logistic models were gender, age, distance from the place of treatment, MMPI depression score and the binary variable categorised as pessimistic or non-pessimistic. All analyses used a generalised estimating equations approach, adjusting the standard errors for the correlation between knees (right and left) within the same patient due to replacement of both knees and/or multiple operations on the same knee. Time to revision was assessed by using the time from TKR to the first revision/re-operation on the same knee.

A Cox's proportional-hazards regression model was used to compare the time to revision in pessimists and nonpessimists after adjusting for age, gender, distance from the place of treatment and depression score. The Cox survival analysis was performed using a robust estimate of variance to account for correlated joints within the same patient.

The characteristics of survey responders and nonresponders were compared using logistic regression analyses on whether or not the patient had or did not have an MMPI. The odds ratio or hazard ratio with $95 \%$ confidence intervals (CI) are reported from these regression analyses, and p-values $<0.05$ were considered significant. A 95\% CI for the odds or hazard ratio that includes unity represents a non-significant association. Analyses were performed using SAS 9.1.3 (SAS Institute Inc., Cary, North Carolina) and Stata 10.0 (StataCorp LP, College Station, Texas).

\section{Results}

We studied 702 patients with 894 primary TKRs and completed MMPIs who had responded to follow-up pain and functional activity questionnaires; there were 783 knees with completed surveys at two years and 443 at five years after surgery. The number of completed surveys exceeded 894 , as some patients responded to both two- and five-year pain and functional activity surveys. Other characteristics of the cohorts are described in Table I. Similarly, there were 164 revision TKR patients with completed MMPIs who had responded to follow-up pain and functional activity questionnaires; 144 had completed surveys at two years and 79 had completed pain and function surveys at five years post-operatively. Mean T-scores for patients from 1962 to 1965 were 56 for women and 57 for men similar in age to our cohort. ${ }^{27,28}$

For the primary TKR two-year follow-up cohort, the mean age at operation was 68.8 years (29 to 93), 300 $(38 \%)$ were men, $96(12 \%)$ had a normal BMI of $<25$, the underlying diagnosis was osteoarthritis in $732(93 \%)$, and a cemented implant was used in $769(98 \%)$. The MMPI was administered a mean of 17 years before the primary TKR (Table I). Characteristics of other cohorts are summarised in Table I.
Patients in the primary two-year follow-up group with an MMPI were significantly less likely than those without an MMPI to be male ( $\mathrm{p}<0.01, \mathrm{p}<0.01, \mathrm{p}=0.04$, $\mathrm{p}<0.01, \mathrm{p}<0.01)$, odds ratio, 0.76 (95\% CI 0.63 to 0.91 ), to live $>100$ to 500 miles or $>500$ miles from the place of treatment (relative to $<100$ miles), odds ratio 0.72 (95\% CI 0.60 to 0.87$)$ and odds ratio 0.68 (95\% CI 0.47 to 0.98$)$, respectively. In addition, they were more likely to have higher comorbidity, odds ratio $1.88(95 \%$ CI 1.59 to 2.22) for five-point increase in Deyo-Charlson inde ${ }^{29}$ which is a validated measure of comorbidity that consists of a weighted scale of 17 comorbidities expressed as a summative score, and American Society of Anaesthesiology (ASA) ${ }^{30}$ scores of 3 to 4 (relative to 1 to 2), odds ratio 1.38 (95\% CI 1.17 to 1.63 ). There were no significant $(p>0.40)$ effects of age, operative diagnosis or BMI. Pessimistic explanatory style and outcomes two years after primary TKR. In all, 35 of $222(16 \%)$ of pessimists compared to 52 of $533(10 \%)$ of non-pessimists had moderatesevere pain two years after primary TKR. Furthermore, the odds of moderate-severe pain were 2.21 times greater in pessimists than in non-pessimists in the multivariateadjusted logistic model, which is statistically significant $(\mathrm{p}=0.02)$ (Table II).

A total of 173 of $222(78 \%)$ of pessimists, compared to 457 of $532(86 \%)$ of non-pessimists, reported significant improvement in their knee function, that is, they considered they were much better at the two-year follow-up. Multivariate-adjusted odds of improvement at two years were significantly lower in pessimists for pain at two years in primary TKR, $\mathrm{p}=0.04$, odds ratio 0.53 (95\% CI 0.30 to 0.96$)$.

It was found that 72 of $220(33 \%)$ of pessimists, compared to 136 of $523(26 \%)$ of non-pessimists, reported moderate or severe limitation of activity two years after primary TKR which was not significantly different, odds ratio 1.01 (95\% CI, 0.62 to $1.66 ; \mathrm{p}=0.97$ ) (Table II).

Pessimistic explanatory style and outcomes five years after primary TKR. There were no significant differences between pessimists and non-pessimists with regard to moderate or severe knee pain, odds ratio 1.21 (95\% CI 0.51 to 2.83$)(\mathrm{p}=0.67)$ (Table II), and improvements in knee function were not significantly different between pessimists and non-pessimists, odds ratio 1.26 (95\% CI 0.57 to 2.77$)(\mathrm{p}=0.57)$. Although the association of pessimism with limitation of activity at five years was not statistically significant (odds ratio 1.84 (95\% CI 0.98, 3.43) $(\mathrm{p}=0.06))$, the upper limit of the CI indicated that the odds of limitation of activity could be more than three times greater in pessimists.

Pessimistic explanatory style and revision rates after primary TKR. There was a lowered, albeit non-significant, association of pessimism and the risk of revision, hazard ratio $0.8(95 \%$ CI 0.39 to 1.64$)(\mathrm{p}=0.55)$. More specifically, the revision rates at five-year follow-up were $2 \%$ for pessimists and $3 \%$ for non-pessimists, and $8 \%$ and $7 \%$ at ten-year follow-up, respectively. 
Table I. Demographic and clinical characteristics of the study cohort

\begin{tabular}{|c|c|c|c|c|}
\hline & \multicolumn{2}{|c|}{ Primary total knee replacement } & \multicolumn{2}{|c|}{ Revision total knee replacement } \\
\hline & 2-year $(n=783)$ & 5 -year $(n=443)$ & 2-year $(n=144)$ & 5 -year $(n=79)$ \\
\hline Mean age at surgery, years (SD) & $68.8(9.7)$ & $68.9(9.3)$ & $67.2(9.6)$ & $67.2(9.7)$ \\
\hline Years from $\mathrm{MMPI}^{*}$ to surgery, mean (SD) & $17.4(9.4)$ & $16.2(9.7)$ & $17.2(8.9)$ & $16.7(9.0)$ \\
\hline T-score for pessimism, mean $(S D)^{\dagger}$ & $54.2(10.5)$ & $54.5(10.5)$ & $55.1(10.4)$ & $55.0(10.0)$ \\
\hline T-score for depression, mean (SD) & $57.7(11.0)$ & $57.9(11.3)$ & $58.7(11.7)$ & $58.4(11.3)$ \\
\hline \multicolumn{5}{|l|}{ Age groups in years $(\%)$} \\
\hline$\leq 60$ & $144(18.4)$ & $72(16.3)$ & $36(25.0)$ & $19(24.1)$ \\
\hline$>60$ to 70 & $257(32.8)$ & $162(36.6)$ & $44(30.6)$ & $26(32.9)$ \\
\hline$>70$ & $382(48.8)$ & $209(47.2)$ & $64(44.4)$ & $34(43.0)$ \\
\hline \multicolumn{5}{|l|}{ Body mass index $\left(\mathrm{kg} / \mathrm{m}^{2}\right)(\%)$} \\
\hline$\leq 25$ & $96(12.3)$ & $57(13.0)$ & $15(10.4)$ & $4(5.1)$ \\
\hline 30 to 34.9 & $215(27.6)$ & $118(26.9)$ & $50(34.7)$ & $21(26.6)$ \\
\hline 35 to 39.9 & $111(14.3)$ & $60(13.7)$ & $20(13.9)$ & $15(19.0)$ \\
\hline$\geq 40$ & $67(8.6)$ & $39(8.9)$ & $6(4.2)$ & $3(3.8)$ \\
\hline Missing information & 5 & 4 & & \\
\hline \multicolumn{5}{|l|}{$\mathrm{ASA}^{\ddagger}$ score $(\%)$} \\
\hline Class I and II & $396(50.6)$ & $217(49.0)$ & $73(50.7)$ & $45(57.0)$ \\
\hline Class III and IV & $386(49.4)$ & $226(51.0)$ & $71(49.3)$ & $34(43.0)$ \\
\hline Missing information & 1 & & & \\
\hline Charlson index, mean (SD) & $1.8(2.3)$ & $1.7(2.2)$ & $1.5(2.3)$ & $1.0(1.7)$ \\
\hline Cemented (\%) & & & Not applicable & \\
\hline Yes & 769 (98.3) & $442(99.8)$ & & \\
\hline Hybrid & $13(1.7)$ & $1(0.2)$ & & \\
\hline Missing information & 1 & & & \\
\hline \multicolumn{5}{|l|}{ Operative diagnoses $(\%)$} \\
\hline Rheumatoid arthrits or other inflammatory arthritic conditions & $28(3.6)$ & $22(5.0)$ & & \\
\hline Loosening/wear or osteolysis & & & $88(61.1)$ & $45(57.0)$ \\
\hline Osteoarthritis & $732(93.5)$ & 409 (92.3) & & \\
\hline Dislocation, bone or prosthesis, fracture, instability, nonunion & & & $25(17.4)$ & $18(22.8)$ \\
\hline Other & $23(2.9)$ & $12(2.7)$ & & \\
\hline Failed prior replacement with components removed or infection & & & $31(21.5)$ & $16(20.3)$ \\
\hline
\end{tabular}

Pessimistic explanatory style and outcomes two and five years after revision TKR. There were no significant differences with regard to moderate or severe pain between pessimists and non-pessimists at the two-year follow-up of revision TKR (Table III). Pessimists were significantly less likely to report improvement in knee function two years post revision TKR, odds ratio 0.3 (95\% CI 0.11 to 0.85 ) $(\mathrm{p}=0.02)$. In multivariate-adjusted logistic regression analysis there was no significant association between pessimist/ non-pessimist and moderate or severe functional limitation at two-years.

The small number of patients at five-year follow-up following revision TKR (79), precluded multivariate analyses.

\section{Discussion}

This is the first study to examine the association between the pre-existing psychological trait of a pessimistic explanatory style identified on the optimism-pessimism scale of the MMPI years before surgery, and long-term outcomes of self-reported pain and joint function following TKR.

We found that 'pessimistic' patients undergoing TKR were twice as likely as non-pessimists to report moderate or severe pain at the two-year follow-up, and, conversely, almost half as likely to report improvement in knee function. It is important to note that scores on the optimism-pessimism scale used to classify our patients were obtained from MMPIs that had been completed a median of 15 to 17 years before their primary TKR. This has important implications.

First, our data identify a pessimistic explanatory style as a psychological risk factor of significance for poor outcomes at two-year follow-up after primary TKR. Knowledge of the patient's explanatory style can inform the surgeon and patient, allowing both to have realistic expec- 
Table II. Association ${ }^{*}$ of pessimism and outcomes after primary total knee replacement

\begin{tabular}{|c|c|c|c|c|c|c|}
\hline & \multicolumn{3}{|l|}{ Two-year } & \multicolumn{3}{|l|}{ Five-year } \\
\hline & $\bar{n} / N^{\dagger}(\%)$ & Odds ratio $\left(95 \% \mathrm{Cl}^{\ddagger}\right)$ & $\overline{\text { p-value }}$ & $n / N^{\dagger}(\%)$ & Odds ratio $(95 \% \mathrm{Cl})$ & p-value \\
\hline \multicolumn{7}{|c|}{ Moderate-severe pain } \\
\hline \multicolumn{7}{|c|}{ Pessimist } \\
\hline No & $52 / 533(10)$ & 1.0 & & $34 / 306(11)$ & 1.0 & \\
\hline Yes & $35 / 222(16)$ & 2.21 (1.12 to 4.35$)$ & 0.02 & $18 / 126(14)$ & 1.21 (0.51 to 2.83$)$ & 0.67 \\
\hline \multicolumn{7}{|c|}{ Best improvement in knee function } \\
\hline \multicolumn{7}{|c|}{ Pessimist } \\
\hline No & $457 / 532(86)$ & 1.0 & & $255 / 305(84)$ & 1.0 & \\
\hline Yes & $173 / 222(78)$ & $0.53(0.30$ to 0.96$)$ & 0.04 & $100 / 123(81)$ & 1.26 (0.57 to 2.77$)$ & 0.57 \\
\hline \multicolumn{7}{|c|}{ Moderate-severe functional limitation } \\
\hline \multicolumn{7}{|c|}{ Pessimist } \\
\hline No & $136 / 523(26)$ & 1.0 & & $95 / 298(32)$ & 1.0 & \\
\hline Yes & $72 / 220(32.7)$ & $1.01(0.62$ to 1.66$)$ & 0.97 & $53 / 123(43)$ & 1.84 (0.98 to 3.43$)$ & 0.06 \\
\hline
\end{tabular}

Table III. Association ${ }^{*}$ of pessimism and outcomes after revision total knee replacement

\begin{tabular}{|c|c|c|c|}
\hline & \multicolumn{3}{|l|}{ Two-year } \\
\hline & $\bar{n} / N^{\dagger}(\%)$ & Odds ratio $\left(95 \% \mathrm{Cl}^{\ddagger}\right)$ & p-value \\
\hline \multicolumn{4}{|c|}{ Moderate-severe pain } \\
\hline \multicolumn{4}{|c|}{ Pessimist } \\
\hline No & $32 / 97$ (33) & & \\
\hline Yes & $11 / 41(27)$ & $1.16(0.34$ to 3.98$)$ & 0.82 \\
\hline \multicolumn{4}{|c|}{ Best improvement in knee function } \\
\hline \multicolumn{4}{|c|}{ Pessimist } \\
\hline No & $66 / 98(67)$ & & \\
\hline Yes & $18 / 39(46)$ & $0.30(0.11$ to 0.85$)$ & 0.02 \\
\hline \multicolumn{4}{|c|}{ Moderate-severe functional limitation } \\
\hline \multicolumn{4}{|c|}{ Pessimist } \\
\hline No & $48 / 99$ (48) & & \\
\hline Yes & $22 / 38(58)$ & 0.91 (0.34 to 2.47$)$ & 0.85 \\
\hline
\end{tabular}

* multivariate logistic regression models adjusted for gender, age, distance from medical centre, depression scores and pessimism. Numbers were too small to perform multivariable models for five-year follow-up

$\dagger$ totals do not add up to 144 at two-years and 79 at five-years owing to missing responses to each of the variables

$\neq \mathrm{Cl}$, confidence interval

tations of outcome following primary TKR. Furthermore, these data identify a pessimistic explanatory style as a significant risk even after adjusting statistically for the important already-known mediators of age, gender and selfreported depression. Finally, the twofold magnitude of association is impressive, particularly after adjusting for these demographic and emotional variables.

Our five-year follow-up was completed with smaller sample sizes ( $<80$ events). Lack of differences in outcomes between pessimists and non-pessimists at five years may be due to increased potential for recall bias at five years for pain and change of knee function and/or small sample size. A priori sample size calculations were not possible owing to the lack of previously published data for pessimism scales in TKR patients. However, it may also be due to unknown mediators or moderators, or even a frank lack of an association, all requiring further follow-up at longer intervals and with larger samples.

Our study was limited in several ways. First, there are likely to be unknown biases among the physicians who asked patients to complete an MMPI. However, explanatory style is unlikely to have biased completion and return rates for the MMPIs among the medical outpatients included in our study. ${ }^{31}$ Similar biases among patients may pertain to completion of the self-report pain and functional activity questionnaires. Also, for most of our patients 
several years had elapsed between the completion of the MMPI and the TKR and an additional two to five years for the self-report checklists of pain, functional and activity limitations. Thus, other, unknown, stressors and comorbidities may have affected the follow-up report. Nevertheless, Seligman's theory postulates pessimism to be an enduring trait among medical outpatients, and validated here over a 30-year follow-up. Additional follow-up visits between two and five years would have been informative to allow us to discern when the relationship between pessimism and outcome was no longer statistically significant. In addition, our study was completed entirely with retrospective data and the original version of the MMPI. For clinicians or researchers interested in replicating or disputing our findings, a revised version of the optimism-pessimism scale, the optimum-pessimism- $\mathrm{R}^{12}$, has been developed for the MMPI-2, the current version of the original MMPI. Finally, we asked our patients to provide reports on themselves preand post-operatively, and did not make comparisons with general population norms.

There was no statistically significant association between the patient's pessimism status and the moderate-severe functional limitations, such as stair-climbing, at two-year followup, although the lower limit of the odds ratio was very close to 1 and the upper limit indicated that the odds could be more than three times greater in pessimists. It is important to differentiate this result from self-reported improvement of the knee from the pre-operative status, which was significantly higher in non-pessimists at the two-year follow-up.

The self-reported variable for limitation of activity, including stair-climbing, pain while walking and similar activities, assesses the current state, whereas the variable of self-reported change in improvement (Tables II and III) captures the change the patient perceives from their pre-operative condition, which may help explain the differences in results for these two variables. Additionally, limitation of activity after TKR is already known to be affected by comorbid conditions, ${ }^{32-34}$ which, along with increasing age, may partially or completely negate the benefit derived from the TKR over time. In contrast, the improvement in knee function is joint specific and is more likely to be influenced by TKR than any comorbidity.

Two recent studies have shown that a pessimistic explanatory style, as characterised by elevated scores on the optimism-pessimism scale of the MMPI, is associated with higher mortality over time among general medical outpatients ${ }^{13}$ and in a college sample. ${ }^{35}$ Pessimism was also associated with poorer self-reported health in all domains of the Short Form 36 (SF-36) $)^{36}$ in general medical outpatients, ${ }^{14}$ among survivors of head/neck cancer ${ }^{37}$ and breast cancer, ${ }^{38}$ in patients with temporal lobe epilepsy, ${ }^{39}$ and contributed to successful cessation of smoking among medical patients. ${ }^{40}$ Our study adds a post-operative orthopaedic sample to the medical literature on associations between explanatory style and self-reported outcomes.

This is of considerable importance as the main reason for undergoing TKR is pain relief, improvement in function and a better overall quality of life. A pessimistic explanatory style has an adverse impact on these outcomes.

It should be noted that patients who completed an MMPI as part of their evaluation may speculatively be considered to be among the most complex of medical referrals. The MMPI was widely used here as a screening and evaluative measure. Thus, if the examining physician believed there were psychological elements related to the presenting medical symptoms, an MMPI was likely to be obtained as an aid in clarifying such issues.

Apart fom Seligman's theory of explanatory style, studies examining the outcome expectations of patients prior to an intervention suggest that positive expectations are associated with better results and higher patient satisfaction. ${ }^{37-41}$ It is conceivable that explanatory style may have exerted an influence on the expectation of outcome of these patients in these reports. Further study is needed to clarify the association between pre-operative expectation, which is typically termed dispositional optimism, ${ }^{41,42}$ and explanatory style as theorised by Seligman.

How might these findings affect patient care. We speculate that the difference in pain and functional outcomes between pessimists and non-pessimists may be related to lower preoperative expectations, as described above, unhealthy lifestyles that might interfere with rehabilitation after TKR, less rigorous involvement at two-year follow-up leading to suboptimal outcomes, or different perceptions of what constitutes a good outcome. Screening for explanatory style or broad outcome expectations should be considered in patients already known to be at high risk for undergoing TKR, as our data clearly indicate that a pessimistic explanatory style adds to the risk of a poorer outcome. This can inform patients of the expected outcomes and provide support for implementing cognitive-behavioural intervention.

How does this tie in with other literature regarding psychological correlates such as depression or anxiety? In a multinational prospective cohort of 682 patients who completed two-year assessments after primary TKR, preoperative psychological distress, defined as a SF-36 mental health subscale score $<50$, was associated with significant differences in multivariate-adjusted Western Ontario McMaster Universities Arthritis Index (WOMAC) ${ }^{43}$ pain scores at one- and two-year follow-up after primary TKR (3 to 5 points). ${ }^{3}$ No associations were noted with the WOMAC function scale. In another study of 8000 TKRs at a single centre in the United States, lower pre-operative mental component summary score predicted the greatest variation in the Short-Form-12 (SF-12 $)^{44}$ physical component summary score 12 months after TKR, meaning that the pre-operative mental component summary was strongly associated with and predictive of the post-operative physical component summary score. ${ }^{45}$ Ayers et $\mathrm{al}^{5}$ found that the former pre-operative score significantly predicted the latter score at the six-month follow-up after TKR.

Our study identifies another psychosocial characteristic associated with poorer outcomes from TKR. Because 
patients with psychosocial stressors such as depression and anxiety have poor social support and coping strategies, ${ }^{5}$ further studies also need to examine these in patients with a pessimistic explanatory style compared to the nonpessimists, and determine the mechanisms through which they affect outcomes following TKR.

Our findings have implications for developing mental health interventions specific to the issues faced by patients following TKR, suggesting that individuals who have a pessimistic explanatory style may be less resilient in adapting to the challenges of surgery. Whether it is possible to provide cognitive-behavioural interventions specifically for such patients to improve outcomes in terms of pain, function, quality of life and overall satisfaction, needs to be investigated.

Among our patients of both genders who underwent TKR, a pessimistic explanatory style, measured many years before surgery, was associated with significantly higher selfreported pain and less favourable functional outcomes at follow-up, compared to patients classified as having an optimistic, or non-pessimistic, explanatory style. Given the cognitive nature of a pessimistic explanatory style as presented in Seligman's theory, potential interventions for such patients might include psycho-educational and cognitivebehavioural strategies. Pre-operative identification of explanatory style can assist patients and their surgeons in setting a realistic goal after primary TKR.

We thank Y. Loechler of the Mayo Clinic for assistance in data extraction, and S. Harmsen for statistical advice and programming. The authors take full responsibility for the data analysis and presentation. One of the authors (DGL) has received royalties/speaker fees from Zimmer, has been a paid consultant to Zimmer, and has received institutional research funds from DePuy, Stryker and Zimmer. None of the authors have any financial conflict related to this study. Each author certifies that their institution has approved the human protocol for this investigation and that all investigations were conducted in conformity with ethical principles of research.

No benefits in any form have been received or will be received from a commercial party related directly or indirectly to the subject of this article.

\section{References}

1. Brander VA, Stulberg SD, Adams AD, et al. Predicting total knee replacement pain: a prospective, observational study. Clin Orthop 2003;416:27-36.

2. Faller H, Kirschner S, König A. Psychological distress predicts functional outcomes at three and twelve months after total knee arthroplasty. Gen Hosp Psychiatry 2003;25:372-3.

3. Lingard EA, Riddle DL. Impact of psychological distress on pain and function following knee arthroplasty. J Bone Joint Surg [Am] 2007;89-A:1161-9.

4. Ayers DC, Franklin PD, Ploutz-Snyder R, Boisvert CB. Total knee replacement outcome and coexisting physical and emotional illness. Clin Orthop 2005;440:157-61.

5. Ayers DC, Franklin PD, Trief PM, Ploutz-Snyder R, Freund D. Psychological attributes of preoperative total joint replacement patients: implications for optimal physical outcome. J Arthroplasty 2004;19(Suppl 2):125-30.

6. Gillham JE, Shatté AJ, Reivich KJ, Seligman MEP. Optimism, pessimism, and explanatory style. In: Chang E, ed. Optimism \& pessimism: implications for theory research, and practice. Washington: American Psychiatric Association, 2001:53-76.

7. Seligman MEP. Explanatory style: predicting depression. achievement, and health. In: Yapko MD, ed. Brief therapy approaches to treating anxiety and depression. New York: Routledge, 1989.

8. Seligman MEP, Kaman LP, Nolan-Hoeksema S. Explanatory style across the life span: achievement and health. In: Hetherington E, ed. Child development in life-span perspective. Hillsdale: Erlbaum, 1988:91-114.

9. Peterson C, Bossio LM. Optimism and physical well-being. In: Chang E, ed. Optimism \& pessimism: implications for theory, research, and practice. Washington: American Psychiatric Association, 2001:127-45.
10. Hathaway SR, McKinley JC. A multiphasic personality schedule (Minnesota). 1: construction of the schedule.J Psychology 1940;10:249-54

11. Colligan RC, Offord KP, Malinchoc M, Schulman P, Seligman ME. CAVEing the MMPI for an optimism-pessimism scale: Seligman's attributional model and the assessment of explanatory style. J Clin Psychol 1994;50:71-95.

12. Malinchoc M, Offord KP, Colligan RC. Revised optimism-pessimism scale for the MMPI-2 and MMPI. J Clin Psychol 1995;51:205-14

13. Maruta T, Colligan RC, Malinchoc M, Offord KP. Optimists vs pessimists: survival rate among medical patients over a 30-year period. Mayo Clin Proc 2000;75:140-3.

14. Maruta T, Colligan RC, Malinchoc M, Offord KP. Optimism-pessimism assessed in the 1960s and self-reported health status 30 years later. Mayo Clin Proc 2002:77:748-53

15. Hathaway SR, McKinley JC. The Minnesota multiphasic personality inventory. Minneapolis: University of Minnesota Press, 1943

16. Butcher JN, Dahlstrom W, Graham JR, Tellegen A, Kaemmer B. MMPI-2. Minnesota Multiphasic Personality Investory-2: Manual for administration and scoring. Minneapolis, Minnesota, 2001.

17. Butcher JN. A beginner's guide to the MMPI-2. Second ed. Washington: American Psychological Association, 2005

18. NIH Consensus Panel. NIH consensus statement on total knee replacement December 8-10, 2003. J Bone Joint Surg [Am]2004;86-A:1328-35.

19. Kane RL, Saleh KJ, Wilt TJ, Bershadsky B. The functional outcomes of total knee arthroplasty. J Bone Joint Surg [Am]2005;87-A:1719-24.

20. McGrory BJ, Morrey BF, Rand JA, Ilstrup DM. Correlation of patient questionnaire responses and physician history in grading clinical outcome following hip and knee arthroplasty: a prospective study of 201 joint arthroplasties. J Arthroplasty 1996;11:47-57.

21. Mor V, Wilcox V, Rakowski W, Hiris J. Functional transitions among the elderly: patterns, predictors, and related hospital use. Am J Public Health 1994:84:1274-80.

22. Dunlop DD, Semanik P, Song J, et al. Risk factors for functional decline in older adults with arthritis. Arthritis Rheum 2005;52:1274-82.

23. Singh JA, Gabriel S, Lewallen D. The impact of gender, age, and pre-operative pain severity on pain after TKA. Clin Orthop 2008;466:2717-23.

24. Kennedy DM, Hanna SE, Stratford PN, Wessel J, Gollish JD. Preoperative function and gender predict pattern of functional recovery after hip and knee arthroplasty J Arthroplasty 2006;21:559-66.

25. Brander V, Gondek S, Martin E, Stulberg SD. Pain and depression influence outcome 5 years after knee replacement surgery. Clin Orthop 2007;464:21-6.

26. Singh JA, Lewallen D. Age, gender, obesity, and depression are associated with patient-related pain and function outcome after total hip arthroplasty. Clin Rheumatol 2009;28:1419-30.

27. Colligan RC, Osborne D, Swenson WM, Offord KP. The MMPI: a contemporary normative study. New York: Praeger, 1983

28. Swenson WM, Pearson JS, Osborne D. An MMPI source book: basic item, scale, and pattern data on 50000 medical patients. Minneapolis: Universty of Minnesota Press, 1973

29. Deyo RA, Cherkin DC, Ciol MA. Adapting a clinical comorbidity index for use with ICD-9-CM administrative databases. J Clin Epidemiol 1992;45:613-19.

30. Dripps RD, Lamont A, Eckenhoff JE. The role of anesthesia in surgical mortality JAMA 1961:178:261-6.

31. McLeod TG, Costello BA, Colligan RC, et al. Personality characteristics of health care satisfaction survey non-respondents. Int J Health Care Qual Assur 2009:22:145-56.

32. Jones CA, Voaklander DC, Johnston DW, Suarez-Almazor ME. The effect of age on pain, function, and quality of life after total hip and knee arthroplasty. Arch Intern Med 2001;161:454-60.

33. Lingard EA, Katz JN, Wright EA, Sledge CB; Kinemax Outcomes Group. Predicting the outcome of total knee arthroplasty. J Bone Joint Surg [Am] 2004;86A:2179-86.

34. Wasielewski RC, Weed H, Prezioso C, Nicholson C, Puri RD. Patient comorbidity: relationship to outcomes of total knee arthroplasty. Clin Orthop 1998;356:85-92.

35. Brummett BH, Helms MJ, Dahlstrom WG, Siegler IC. Prediction of all-cause mortality by the Minnesota Multiphasic Personality Inventory Optimism-Pessimism scale scores: study of a college sample during a 40-year follow-up period. Mayo Clin Proc 2006:81:1541-4. 
36. Ware JE Jr, Sherbourne CD. The MOS 36-item short-form health survey (SF-36). 1: conceptual framework and item selection. Med Care 1992;30:473-83.

37. Kung S, Rummans TA, Colligan RC, et al. Association of optimism-pessimism with quality of life in patients with head and neck and thyroid cancers. Mayo Clin Proc 2006;81:1545-52

38. Petersen LR, Clark MM, Novotny P, et al. Relationship of optimism-pessimism and health-related quality of life in breast cancer survivors. J Psychosoc Oncol 2008;26:15-32.

39. Hermann BP, Trenerry MR, Colligan RC. Learned helplessness, attributional style, and depression in epilepsy: Bozeman Epilepsy Surgery Consortium. Epilepsia 1996;37:680-6.

40. Ames SC, Vickers KS, Decker PA, et al. Select Minnesota Multiphasic Personality Inventory (MMPI) scales as predictors of tobacco abstinence following treatment of nicotine dependence. Psychology and Health 2005;20:331-52.
41. Carver CS, Scheier MF. Optimism, pessimism, and self-regulation. In: Chang E, ed. Optimism \& pessimism: implications for theory, research, and practice. Washington: American Psychology Association, 2001:31-49.

42. Scheier MF, Carver CS, Bridges MW. Optimism, pessimism, and psychological well-being. In: Chang E, ed. Optimism \& pessimism: implications for theory, research, and practice. Washington: American Psychology Association, 2001:189-216.

43. Bellamy N, Buchanan WW, Goldsmith CH, Campbell J, Stitt LW. Validation study of WOMAC: a health status instrument for measuring clinically important patient relevant outcomes to antirheumatic drug therapy in patients with osteoarthritis of the hip or knee. J Rheumatol 1988;15:1833-40.

44. Ware J Jr, Kosinski M, Keller SD. A 12-item Short-Form Health Survey: construction of scales and preliminary tests of reliability and validity. Med Care 1996;34:220-33.

45. Franklin PD, Li W, Ayers DC. The Chitranjan Ranawat Award: functional outcome after total knee replacement varies with patient attributes. Clin Orthop 2008;466:2597-604 